\title{
Los diccionarios compendiados o abreviados del siglo XIX
}

\author{
M. ${ }^{a}$ DEL CARMEN ÁVILA MARTÍN
}

Universidad de Granada

\section{INTRODUCCIÓN}

Entre la variedad de diccionarios ${ }^{1}$ que aparecen en el siglo XIX nos detendremos en un grupo de obras que se caracterizan por ser reducciones de obras mayores con fines comerciales o sociales, pues se trataba de obras menos costosas que los diccionarios de los que procedían. La reducción o el compendio de obras mayores ha sido práctica habitual durante todo el siglo XX pero hunde sus raíces en el siglo XIX. La demanda de diccionarios reducidos está motivada por la extensión de las ideas de la revolución francesa que propugnaba la instrucción universal, el aprendizaje de las lenguas y que activó la elaboración de obras adaptadas a las necesidades de un número creciente de usuarios.

Los diccionarios abreviados o compendiados son obras de carácter menor, pues surgen de proyectos lexicográficos de más envergadura y su mérito es la transmisión de los valores que esos proyectos hayan podido aportar a la historia de la lexicografía. Además cumplieron una función social al extender el conocimiento a sectores sociales más amplios. Por otro lado, se caracterizan por el empleo de ciertas técnicas específicas. La evolución de la técnica lexicográfica de los diccionarios de aprendizaje en nuestros días ha censurado el recorte como un mecanismo poco adecuado para la realización de diccionarios, aunque ha sido práctica habitual de muchas editoriales hasta bien entrado el siglo XX. La evolución de la técnica lexicográfica en el siglo XIX produjo también cambios en la evolución de estas obras que reflejan los producidos en la lexicografía general de la época.

\section{DICCIONARIOS GENERALES Y DICCIONARIOS ABREVIADOS}

La lexicografía del siglo XX está marcada por hechos de carácter puramente lexicográfico, y también de carácter histórico. Según Martínez Marín (2000), entre los de

${ }^{1}$ Véase Azorín (1996-1997), Martínez Marín (2000) y Seco (2003).

M. DEL CARMEN ÁVILA MARTÍN, «Los diccionarios compendiados y abreviados del siglo XIX»,

Revista de Lexicografia, XVI (2010), pp. 7-20 ISSN: 1134-4539, e-ISSN: 2603-667. DOI: https://doi.org/10.17979/rlex.2010.16.0.3794 
carácter lexicográfico hay que señalar la influencia francesa; y entre los de carácter histórico se sitúa, en primer lugar, el proceso de independencia de las naciones americanas $\mathrm{y}$, en segundo lugar, la influencia del racionalismo filosófico o las novedades culturales, científicas y técnicas, que dan lugar a la aparición del enciclopedismo, así como la influencia de las ideas románticas que propicia la aparición de vocabularios regionales.

Entre los hechos históricos cabe también destacar el abandono del latín como lengua de la enseñanza. A principios del siglo XIX se implanta el castellano en todos los niveles educativos. En esta época se introducen en España las ideas de la Revolución francesa que difunden los principios de universalidad, uniformidad y gratuidad de la instrucción pública, aunque las reformas no tuvieron continuidad, como es sabido (Capitán 2002). Los avances en la enseñanza general tuvieron un carácter gradual, con sucesivos avances y retrocesos, y los diccionarios jugaron un papel importante en este desarrollo, pues constituían un pilar imprescindible en el aprendizaje de la lengua. Ante la existencia de nuevas necesidades, la instrucción pública, comienzan a publicarse obras que cubren esa demanda.

Los acontecimientos históricos fueron la causa de que muchas de esas obras se publiquen inicialmente en Francia. Además, a finales del siglo XVIII las revueltas en el país vecino provocaron la crisis del mercado editorial y se frustró la realización de grandes proyectos. Sin embargo, como señala Pruvost (2002: 44) se favorece en la lexicografía francesa la aparición de diccionarios abreviados. ${ }^{2}$ Este tipo de obras fueron muy numerosas e influyeron indudablemente en la aparición de obras en español que reducen el diccionario de la Academia. Entre los más célebres está el Nouveau vocabulaire françois ou abrégé du Dictionnaire de l'Academie de De Wailly, padre e hijo, con 22 ediciones de 1801 a 1855. En el siglo que va de 1760 a 1860 , Quemada catalogó más de una centena de diccionarios que hacían mención a la Academia en su título: «le développement progresif du système scolaire renforce la prolifération de ce type d'ouvrages qui, de manière générale, a largement contribué à la diffusion de la langue française» (Pruvost 2002: 45).

La reducción de diccionarios con la finalidad de difundir sus contenidos y favorecer un mejor acceso al conocimiento es el mérito de estas obras, no sólo en el ámbito galo, sino también en el ámbito hispánico.

\section{EL DICCIONARIO DE LA ACADEMIA}

En nuestro país, ya desde finales del siglo XVIII se realizan reducciones de obras más extensas ante la demanda creciente. La reducción del diccionario de Autoridades y

${ }^{2}$ La lexicografía francesa abreviada se caracteriza según Pruvost (2002: 45) por nomenclaturas poco abreviadas en relación a los diccionarios de los que proceden, y por una disminución drástica de las informaciones en el contenido de los artículos. 
la publicación en 1780 del Diccionario de la lengua castellana reducido a un tomo para su más fácil uso es, posiblemente, una de las razones de su éxito editorial y de su permanencia hasta nuestros días. Esa reducción, según Seco, se hizo ante la dificultad de realizar una revisión del Diccionario de Autoridades que se podía prolongar durante decenios a tenor de la lentitud de los trabajos y al estar próxima a agotarse la edición del diccionario completo. Se propuso así la edición de un compendio de toda la obra, en menor número de tomos y tipografía más reducida y suprimiendo las etimologías y las autoridades que andando el tiempo ha sido denominado sin más el «Diccionario de la Academia» pero que en su origen «se apellidaría vulgar, usual o común, y que sus propios compiladores llamaron compendio» (Seco 2003: 240).

La influencia de la Academia se hizo sentir a lo largo de todo el siglo. Como ha señalado Seco, la edición del Diccionario de la Academia de 1780 en un solo tomo tuvo un éxito fulgurante. La obra se editó en diez ocasiones a lo largo del siglo XIX. Y si bien al principio tuvo escasos competidores, a partir de la década de los años cuarenta surgen una gran cantidad de diccionarios que le hacen la competencia: es el nacimiento de la lexicografía no académica en la península.

El proceso se había iniciado décadas antes en Francia, cuando los editores franceses descubrieron el mercado americano, y los numerosos intelectuales exiliados se convirtieron en redactores de diccionarios, entre ellos, Vicente Salvá (Seco 2003: 260-261). Además el ejemplo francés hizo que algunos escritores y editores intentaran implantar el mismo sistema entre nosotros (Seco 2003: 161).

Por otro lado, ya en 1831 señalaba Andrés Bello que hacen falta libros para la instrucción de la juventud ${ }^{3}$ y esa afirmación programática hizo que «los editores del país vecino dieran comienzo a esta aventura lexicográfica, que tiene como objetivo primordial satisfacer la demanda del público hispanohablante del otro lado del atlántico» (Azorín 1996: 113). Se creaban así las condiciones necesarias para la aparición en el mercado peninsular de lo que, ya en nuestro siglo, se ha denominado lexicografía didáctica.

${ }^{3}$ Según señala Azorín, Andrés Bello, «En una carta dirigida a Mendíbil, fechada en Santiago de Chile en 1831, daba cuenta de la situación de la creciente demanda de bienes de cultura que se estaba produciendo en los países de Iberoamérica, viniendo a corroborar la existencia de ese amplio mercado que allí se abría para los editores europeos: Entre las innumerables faltas y privaciones a que estamos condenados en esta parte del mundo - escribe Bello - no es menos persistente y perjudicial la de libros útiles y elementales para la instrucción de la juventud [...]. Yo he propuesto al gobierno como medio de suplir esta falta, el de hacer traducir e imprimir en Europa las obras modernas más acreditadas [...] y he creído que pudiera convenir a algunos de los españoles emigrados que hay en París y Londres, entre os cuales sé que los hay de mucha instrucción y que manejan la lengua patria con la corrección y pureza necesaria, el encargarse de este trabajo» (1996: 113). 


\title{
4. LOS DICCIONARIOS ABREVIADOS: COMPENDIADOS, MANUALES O PORTÁTILES
}

A lo largo del siglo XIX aparecen diccionarios que se pueden adscribir a diferentes tipologías (Martínez Marín 2000), entre los que se han señalado diccionarios enciclopédicos, diccionarios generales y diccionarios abreviados. ${ }^{4}$ Estos últimos, los diccionarios abreviados, estaban dirigidos a los jóvenes que se adiestraban en el aprendizaje de la lengua materna, mientras los diccionarios generales y los enciclopédicos se destinaban a un público general. Los diccionarios generales reproducen también el diccionario de la Academia, pero los diccionarios compendiados tienen como objetivo reducir el tamaño por lo que el recorte es sistemático. La técnica utilizada para superar al diccionario de la Academia fue, sobre todo a partir de la década de los cuarenta, censurar la ausencia de voces e imitar el afán acumulativo de los diccionarios franceses. Además en este siglo es cuando aparece el diccionario enciclopédico (Alvar Ezquerra 1997, Azorín Fernández 1996-1997, Martínez Marín 2000) y la reducción o compendio afectará también a este tipo de obras.

El adjetivo de portátil aparece en diccionarios bilingües, destinados al aprendizaje de segundas lenguas. Su uso evoca la idea de viaje y sugiere un manejo más fácil. En este sentido, la mayoría de los diccionarios que aparecen en el Catálogo del Patrimonio Bibliográfico Español bajo la denominación de portátiles son bilingües, ${ }^{5}$ aunque en alguna ocasión aparece esta denominación en un diccionario abreviado de la lengua castellana publicado también en Francia. ${ }^{6}$

Entre los diccionarios que forman parte de ese grupo se ha citado el de Vicente González Arnao (1926). Azorín (2006) lo incluye en el grupo de obras que se inspiran en la edición del Diccionario Académico de 1822.7 Y aunque se agrupan como diccionarios generales de la lengua, la descripción que se ofrece de este nos aporta datos de su condición de diccionario abreviado, ya que la obra presenta una ligera remodelación del contenido de la sexta edición del $D R A E$ :

\begin{abstract}
Así, por ejemplo, reduce el número de acepciones y sintetiza las definiciones de la Academia. También - y cosa discutible - se elimina del diccionario toda referencia al nivel de uso, ámbito de especialidad, estado de lengua, etc. Según esto, parece ser que la idea del autor consistía en compendiar, despojándolo de la información no fundamental, el Diccionario de la RAE (Azorín 2006: 6).
\end{abstract}

Las circunstancias políticas de la península después de la guerra de la Independencia y el periodo absolutista no favorecían el mercado peninsular. Por su parte, las ideas liberales suponen la implantación de la instrucción pública y la adopción del castellano

\footnotetext{
${ }^{4}$ A ellos se añade el de sinónimos, el ideológico, el etimológico y el ilustrado (Martínez Marín 2000).

${ }_{5}^{5}$ Así, por ejemplo, Gattel (1803), Aquenza (1890), el Diccionario portátil español-inglés (1852), y Booch-Arkossy (1877).

${ }^{6}$ Diccionario portátil de la lengua castellana (1873).

7 Junto con el de Pla y Torres (1826), Núñez de Taboada (1825) y José René Mason (1826).
} 
como lengua de la enseñanza, por lo que más tarde aumenta la demanda de diccionarios, tanto para el público en general como para el uso en la enseñanza.

Cuando las complejas circunstancias lo permitieron, algunas de estas obras, que se publicaron inicialmente en París, se publican en Madrid, como es el caso del Diccionario de la lengua castellana, por la Real Academia Española, compendiado por Cristóbal Pla y Torres publicado en París (1826) y unos años más tarde en Madrid (1840).

Esta obra se cita como un diccionario general que se limita a reproducir el diccionario de la Academia. ${ }^{8}$ Es el primero que se publica después del Diccionario de la lengua castellana (1825) de Núñez de Taboada. Utiliza el prestigio de la Academia, cuyo nombre reproduce sin pudor en el título. Pero los destinatarios del diccionario están claramente identificados en el prólogo de los editores, los jóvenes que comienzan sus estudios:

En una palabra, los Editores no se han propuesto sino publicar una obra que pueda manejarse por toda clase de persona, con facilidad y frecuencia. Será muy útil, particularmente para los jóvenes Americanos y Españoles que empiezan sus estudios, debiendo, como parece regular, principiarlos por el de la lengua nativa (Pla y Torres 1840: VI).

Vicente Salvá, desde su trabajo editorial, conocía las demandas del público hispanoamericano y se sumó a la corriente francesa de la edición de obras adaptadas. Publicó así un diccionario en París (1837) que era una versión corregida de la octava edición del Diccionario de la lengua castellana de la Real Academia Española. Esa obra fue el inicio de la publicación posterior, el Nuevo diccionario de la lengua castellana (1846), versión ampliada que ha sido valorada como el inicio de la corriente no académica y como uno de los mejores diccionarios monolingües del español (Azorín 2006).

El aumento de la demanda hace que aparezcan otros diccionarios que llevan por adjetivo calificativo el de manual y que hace referencia también a su facilidad de manejo. El primero de ellos es el Novísimo diccionario manual de la lengua castellana por una sociedad de literatos (1846), que presenta un tamaño muy reducido y técnicas de abreviación drásticas. Esta obra recoge en la portada la leyenda «Todo lo útil; Nada supérfluo».

A partir de los años cuarenta del siglo XIX se inicia el afán acumulativo que caracterizaba a la lexicografía francesa. La obra que inicia la corriente enciclopédica es el Diccionario Nacional o Gran Diccionario clásico de la lengua castellana (1846-1847) de Ramón Joaquín Domínguez y que tiene su ilustre antecesor en el diccionario de Terreros. Sin embargo, estas obras eran muy voluminosas y también fueron compendiadas y reducidas para un manejo más fácil.

Otro diccionario compendiado, en el que aparece la denominación de manual es el de Ramón Campuzano (Madrid 1850), Diccionario manual de la lengua castellana arreglado a la ortografía de la Academia Española y el más completo de cuantos se

8 A veces se hacen de él comentarios muy negativos: «Sin originalidad, basado en el DRAE» (Haensch y Omeñaca 2004: 218). 
han publicado hasta el día. Esta obra sigue siendo un diccionario (y no una enciclopedia) que pretende de abarcar todo el léxico de la lengua, incluido el de las ciencias y las técnicas.

Hacia finales del siglo XIX llega a su plenitud en nuestro país el afán enciclopedista, acumulativo o expansivo que se había desarrollado en la lexicografía francesa desde principios de siglo (Seco 2003: 269). Y aparecen también diccionarios enciclopédicos abreviados como el de Lorenzo Campano (1876) cuyo título es Diccionario general abreviado de la lengua castellana. El más completo de los publicados hasta el día que abraza los términos literarios y los del lenguaje usual en su sentido propio y figurado las voces usadas en las ciencias, artes y oficios y los nombres propios de historia, geografia biografia y mitología.

El último diccionario que consideraremos es el Diccionario popular de la Lengua Castellana (1882) de Felipe Picatoste. Este diccionario abreviado que se publica a finales del siglo XIX con un propósito pedagógico rompe con el afán acumulativo de las enciclopedias. Las reediciones, con muy pocas variantes, serán además una constante a medida que se extienda la instrucción pública en el siglo XIX.

\section{LA TÉCNICA LEXICOGRÁFICA DE LOS DICCIONARIOS ABREVIADOS}

El diccionario de la Real Academia Española, como es sabido (Hernando Cuadrado 1997), compendió el Diccionario de Autoridades suprimiendo los ejemplos. Las necesidades de reducción de los diccionarios abreviados utilizan distintos procedimientos, aunque los rasgos más característicos son el menor tamaño ${ }^{9}$, que los hace fáciles de manejar y estar destinados a la enseñanza. Por otro lado, estas obras tendrán distinta fortuna editorial pues a medida que avance el siglo las necesidades educativas dan lugar a un mayor número de ediciones.

El diccionario de Pla (1840), destinado explícitamente a los jóvenes «americanos y españoles» que empezaban sus estudios, se presenta como compendio del diccionario de la Academia (es así un compendio del compendio). El empleo de los materiales académicos, que se indica desde la misma portada, «Diccionario de la Academia española», quiere presentar un trabajo

que ni es una nomenclatura estéril que no explique suficientemente la verdadera significación de las palabras, ni una obra llena de correspondencias inútiles, sino un análisis bien hecho del gran Diccionario de la Academia, omitiendo algunas cosas que fácilmente se suplen, como son los aumentativos y diminutivos, cuando se conocen los nombres primitivos de que se derivan. También se omiten las palabras anticuadas, exceptuando algunas que se conservan todavía en el uso (Pla 1840: VI).

9 El tamaño oscila entre los $11 \times 18 \times 4$ del diccionario de Pla (1840), con 604 páginas, o los $13 \times 17 \times 2.5$ del Novísimo diccionario manual (1846), de 570 páginas. 
Entre las simplificaciones, se reducen las abreviaturas aproximadamente a la mitad y desaparecen abreviaturas de materia y de carácter gramatical. Entre las de materia, se suprimen Voz de la Artillería, Voz de la Ballestería, Voz de Blasón, Voz de Cabestrería, etc. Y entre las de carácter gramatical, los tipos de adverbios, de modo, lugar, etc. solo se recogen con la abreviatura $a d v$.; también desaparecen $a m b$. 'ambiguo' o irreg. 'irregular', entre otras.

En cuando a la macroestructura, reproduce la del diccionario académico, pero la extensión se reduce a una tercera parte. En un cálculo aproximado, se recogen unas treinta y cinco mil entradas. No hay prácticamente reelaboración, sino reducción del diccionario académico que como se indica desde el mismo título, se compendia. La reducción se consigue con la eliminación de numerosas entradas, además de las derivadas. Se eliminan nombres propios, aunque formen parte de la fraseología (Aaron); las palabras anticuadas marcadas por la Academia como tales (abajar, abajarse, aballado, aballar, etc.); los participios de pasado, aunque se recogen si tienen un uso adjetivo (por ejemplo, abarquillado); derivados fácilmente deducibles (por ejemplo, se suprimen abarcador y abarcadura). También se elimina fraseología y refranes; muchos términos técnicos (aunque mantiene otros, como abromado o abceso) y se suprimen las equivalencias latinas de los lemas definidos por la Real Academia.

En la microestructura recoge la información gramatical en abreviatura, así como algunas indicaciones sobre el uso o la materia al igual que el Diccionario de la Academia, e incorpora, como hemos señalado, un solo lema con diferentes acepciones separadas por un guion, tal como se hacía en los diccionarios franceses. ${ }^{10}$

En definitiva, un trabajo de poda que se traslada también a las definiciones. En algunos casos, esa brevedad que se quiere imprimir al diccionario le hace dar definiciones tan escueta como

ABEDUL s. m. Árbol.

ABEJARRÓN s. m. Insecto.

ACACIA s.f. Arbusto.

Elabora muy poco la información que extrae de la Academia. Pero en algún caso hemos detectado la inclusión de indicaciones sobre el uso. La indicación fam. ('familiar') para las voces aburujarse o absoluta no está en el diccionario de la Academia y son añadidos del autor.

En otros casos, la brevedad que se quiere imprimir a la obra le hace reelaborar la definición de forma muy diferente a la Academia.

ABUBILLA s.f. Ave muy conocida, poco mayor que un tordo, de pluma dorada, negra, roja y blanca. En la cabeza tiene un penacho o garzota de pluma de los mismos colores. Es muy agradable a la vista; pero sucia, de mal olor, y de canto desapacible. Upupa Epos. (DRAE-1822).

${ }_{10}$ Así, por ejemplo, el Nouveau vocabulaire François ou abrégé du Dictionnaire de l'Academie de De Wailly, que tuvo 22 ediciones entre 1801 y 1855 (en línea: [http://gallica.bnf.fr/ark:/12148/bpt6k573 0026r.image.langES.f25.pagination]). 
ABUBILLA s.f. Ave de paso y solitaria. (Pla 1840).

$Y$ en un caso muy aislado añade a la definición un ejemplo para mayor claridad:

ABONARSE, v.r. Pagar alguna cantidad adelantada: Abonarse en el teatro, etc.

Mientras que la Academia define:

ABONARSE v.r. Pagar alguna cantidad adelantada para concurrir á alguna diversión pública, ó disfrutar de alguna comodidad. Symbolam conferre.

La técnica lexicográfica de la reducción con fines escolares merece alguna consideración, pues elimina información poco útil para determinados niveles. La innovación de incluir las acepciones dentro del mismo lema, que se generalizará posteriormente en la lexicografía del español, es otro mérito de esta pequeña obra que contribuyó al aprendizaje de la lengua.

Algo más breve que la anterior, el Novísimo diccionario manual de la lengua castellana (1846), reduce aún más el número de abreviaturas (solo recoge fam. 'voz familiar' y abreviaturas de carácter gramatical).

Sobre la selección de las entradas, se afirma lo siguiente:

ADVERTENCIA: Cuando se deja pendiente el sentido de una definición debe completarse con la voz inmediata. Se suprimen por regla general: los participios, aumentativos, diminutivos y superlativos; los derivados verbales en miento, or y ora, y able ó ible; las voces anticuadas, las provinciales, las de germanía, las científicas que carezcan de aplicación en el idioma común, y los adverbios en mente (1846: 5).

El recuento aproximado de entradas de esta obra nos da la cifra de unos 35000 lemas. No suprime los nombres propios (véase Aaron) pero sí las provinciales y aquellas de significado fácilmente deducible. El recorte se realiza especialmente en las definiciones, que se abrevian, con lo que abundan las definiciones sinonímicas:

Esparto. m. Yerba.

Espasmo. m. Pasmo.

Especial. adj. Singular

Incluso en algunos casos se incluye la entrada pero no se define por considerarse innecesario (horrible, manotada...). La brevedad y simplicidad que persigue la obra es máxima, con lo que la información es muy escueta en muchos casos. Las definiciones además utilizan el procedimiento de eliminar la voz que viene definida a continuación.

Carpintera. n. Ejercer la

Carpintería. f. Oficio ó tienda de

Carpintero. m. Que trabaja madera.

El ahorro de espacio le lleva a utilizar el recurso del paréntesis para indicar elementos del contorno de la definición. No se trata, sin embargo, de un método consciente y elaborado sino de un método de abreviación y desde luego tampoco es sistemático.

Careto, ta. adj. (caballo) Que tiene una lista blanca. 
Huero. adj. (huevo) Que no produce pollo. || Sin sustancia.

Horra. adj. (yegua, etc.) Que no procrea. \| (res) Para mayoral ó pastor.

Horro, ra. adj. (esclavo) Que alcanza libertad. || Libre.

La separación de acepciones se realiza mediante la doble pleca, al igual que en la edición del Diccionario de la Academia de 1832. No parece manejar la edición más próxima de 1843, ya que esta utiliza un símbolo diferente (un aspa) para separar acepciones.

A partir de mediados del siglo XIX, aunque ya venía siendo una constante en otras tradiciones lexicográficas, se extiende la idea de que los diccionarios tienen que aumentar el caudal léxico y superar así al Diccionario de la Academia. ${ }^{11}$ Los diccionarios abreviados empiezan además a tener un enorme éxito editorial, al mismo tiempo que, a imitación de proyectos mayores, se aumenta el número de entradas.

Así el Diccionario manual de Ramón Campuzano (1850) llegó a tener doce ediciones en catorce años pues en 1866 se publica la décimo segunda edición, lo que supone casi una edición anual. Al mismo tiempo se aumenta el número de entradas hasta unas 60 000, sin embargo mantiene el formato del diccionario manejable. ${ }^{12} \mathrm{El}$ aumento de entradas se hace a costa de incluir unidades léxicas pertenecientes a una determinada ciencia o técnica, pero también palabras anticuadas (abajeza), derivadas (aborrecedero, aborrecedor, aborrecible, aborreciblemente, aborrecido y aborrecimiento) o gentilicios (barcelonés, filipino). Las definiciones son frecuentemente de carácter sinonímico muy simplificadas y se disminuye el tamaño de la letra para incluir mayor cantidad de información.

En el último tercio del siglo aparecen diccionarios enciclopédicos abreviados que llegaron a tener también gran éxito editorial. El Diccionario general abreviado de la lengua castellana (1876) de Lorenzo Campano llegó a tener al menos doce ediciones (la última en 1893). El número de entradas se extiende a las 70000 aproximadamente, con la inclusión de topónimos y antropónimos y sigue manteniendo un tamaño reducido. ${ }^{13}$ Naturalmente las dificultades de lectura aumentan pues se reduce la letra considerablemente. Incluye numerosos topónimos y antropónimos entre los que figuran nombres propios de la antigüedad clásica:

Frinis de Mitilene. Poeta y músico que vivió hacia el 480 ánt. de C. J. y añadió dos cuerdas á las siete que entonces tenía la lira.

${ }^{11}$ En el «Prólogo» a la novena edición de 1843, la institución se defiende de las críticas de que es objeto por no incluir voces de las ciencias y las técnicas: «Pero hay también una inmensa nomenclatura de las ciencias, las artes, y profesiones, cuyo significado deben buscar los curiosos en los vocabularios particulares de las mismas; tales voces pertenecen á todos los idiomas y á ninguno de ellos, y si hubieran de formar parte de la lengua común, lejos de ser un libro manual y de moderado precio, circunstancias que constituyen su principal utilidad, sería una obra voluminosa en demasía, semi-enciclopédica, y de difícil adquisición y manejo» (DRAE-1843).

${ }^{12} \mathrm{Su}$ tamaño es de $11 \times 16 \times 5 \mathrm{~cm}$. y contiene 1175 páginas.

${ }^{13} \mathrm{Su}$ tamaño es de $12 \times 18.5 \times 5$ y consta de 1013 páginas. 
Y también personajes de la historia europea (Haraldo, Harcourt) y hasta políticos de la historia reciente:

Hardenberg (Carlos Augusto, príncipe de). Ministro de Negocios extranjeros en Prusia (1750-1822). Favoreció la reacción contra el imperio francés, firmó la paz de París de 1814 y figuró como plenipotenciario en los congresos de Aquisgrán, Carisbad, Viena y Verona.

En los topónimos, en general de ciudades españolas y europeas, se da información sobre su situación geográfica y número de habitantes:

Novara Geogr. Prov. de Italia con cap. de su nombre; esta tiene 22,000 y aquella $58,000 \mathrm{~h}$. La ciudad de Novara es una plaza fuerte de los antiguos Estados Sardos.

En la nomenclatura se recogen también americanismos:

Namore m. bot. Árbol de América.

Nana f. prov. Méjico. Nodriza.

Pizcar. a. fam. Pellizcar. // prov. Méjico. Coger el maíz.

Este afán de incluir el máximo de información en un mínimo espacio fue objeto de crítica ya en su misma época. Felipe Picatoste, en el prólogo del Diccionario popular de la Lengua Castellana censura aquellos «Diccionarios que cuentan pomposamente por muchos miles las voces añadidas. Este aumento es cosa bien fácil, introduciendo los derivados, los aumentativos, los diminutivos y aún los nombres propios, como hacen algunos autores» (1882: 11). Y más adelante afirma: «Tampoco es nuestro propósito hacer un Diccionario enciclopédico en reducido volumen; empresa imposible, que ha convertido algunos libros de este género en un simple catálogo de voces» (1882: 12). Este diccionario, que no está destinado a los estudiantes, sino que tiene como objetivo «ilustrar al obrero y al maestro» se puede también considerar un diccionario de aprendizaje. En su empeño de ser útil, se propone incluir las voces de «uso corriente». Para ese propósito utiliza una técnica empleada con posterioridad, a finales de siglo XX en diccionarios didácticos,$^{14}$ como es señalar con un corchete las palabras que no recoge el DRAE. Entre ellas se encuentran tecnicismos (abcisa, abceso, afonía), palabras coloquiales (achuchón, achulado), raras (adar) y también derivadas (abaniqueo, abaniquería).

Otra novedad de este diccionario es «la indicación de las preposiciones con que, según la Academia Española, se construyen las palabras». El régimen preposicional, si bien siguiendo los dictados de la Academia, se considera una información de utilidad para el aprendizaje.

acompañar, a., (a ,con, de), estar ó ir en compañía $\|$ conducir $\|$ escoltar $\|$ r., (de, con), cantar y tocar siguiendo el tono de alguna voz ó instrumento.

Naturalmente, la evolución de los estudios lingüísticos a lo largo del siglo XX dotará a los diccionarios de aprendizaje de una mayor efectividad en la descripción lin-

${ }_{14}$ El Diccionario didáctico del español. Intermedio, en la edición de 1993 (Maldonado 1993), utiliza un corchete para indicar las palabras que no aparecen en la vigésimo segunda edición del DRAE. 
güística, pero ya están presentes en ellos algunas de las características de la lexicografía didáctica actual.

\section{CONCLUSIONES}

La lexicografía abreviada se extiende en el siglo XIX destinada a la enseñanza y aprendizaje de la lengua materna. Los diccionarios que se publican en este siglo siguen los avatares tanto históricos como lexicográficos que se producen en la época. Son obras destinadas al uso de los jóvenes y por tanto reducciones de diccionarios mayores, tanto en su macroestructura como en su microestructura. Por el mismo motivo, los cambios que se dan en estas obras a lo largo del XIX están relacionados con los cambios que se producen en la lexicografía general.

En sus inicios, por motivos históricos y sociales, empiezan a publicarse en Francia aunque con posterioridad, especialmente a partir de los años cuarenta, se publican también en España. Su objetivo no es enmendar a la Academia, sino ofrecer a los que se inician en el estudio de la lengua materna de un instrumento útil, manejable y menos caro que los diccionarios mayores, para aprender la lengua materna. Tienen consecuentemente un tamaño reducido. La técnica lexicográfica empleada utiliza procedimientos de abreviación. La expansión de la enseñanza de la lengua en castellano justifica la realización de compendios del compendio de la Academia.

Posteriormente, el desarrollo de la lexicografía no académica y el intento de superación de la misma da lugar a la publicación de obras que, a partir de mediados de siglo, intentan superar el caudal léxico del diccionario académico, pero que no aportan ninguna renovación en la técnica lexicográfica. El modelo deja de ser la Academia, aunque sigue presente, pero se imitan otros diccionarios como el diccionario de Salvá o el modelo enciclopedista de Domínguez.

El afán enciclopedista posterior infla las obras hasta convertirlas en enciclopedias, aunque no dejan de ser obras reducidas lo cual mereció también ciertas reservas en algunos autores que veían en esa acumulación simplificada poca utilidad. Hemos de recuperar, sin embargo, la consideración de estos diccionarios cuyo mérito se encuentra en la labor que realizaron en la enseñanza de la lengua, aunque siempre a la sombra de sus hermanos mayores, los diccionarios y las enciclopedias generales. 


\section{REFERENCIAS BIBLIOGRÁFICAS}

\section{DICCIONARIOS}

AQUENZA, Giuseppe (1890): Nuevo diccionario portátil español-francés y francés-español, Leipzig, B. G. Teubner.

BoOCH-ARKOSSY, Friedrich W. (1877): Nuevo diccionario portátil de las lenguas castellana y alemana: el mas completo que se ha publicado hasta el día, Leipzig, B.G. Teubner.

CAMPANO, Lorenzo (1890 ${ }^{10}$ [1876]): Diccionario general abreviado de la lengua castellana, París, Librería española de Garnier Hermanos.

CAMPUZANO, Ramón (1857 [1850]): Diccionario manual de la lengua castellana arreglado a la ortografía de la Academia Española y el más completo de cuantos se han publicado hasta el día, Madrid, Imprenta de D. Ramón Campuzano.

DICCIONARIO PORTÁTIL ESPAÑOL-INGLÉS (1852): Diccionario portátil español-inglés: compuesto sobre las últimas ediciones de Neuman y Baretti: en dos partes: español-inglés, inglés-español, París, Imprenta L. Martinet.

DICCIONARIO PORTÁTIL DE LA LENGUA CASTELLANA (1873): Diccionario portátil de la lengua castellana segun la Academia Española el mas completo de los publicados hasta el día, París, Librería de Garnier Hermanos.

GATTEL, Claude Marie (1803): Nuevo diccionario portátil, español é ingles: compuesto según los mejores diccionarios que hasta ahora han salido a luz en ambas naciones, Valencia, P. J. Mallen.

GonzÁlez ARnAO, Vicente (1826): Diccionario de la Academia española. Edición abreviada por Vicente González Arnao de la última hecha en Madrid en 1822, París, Librería de Parmentier.

Maldonado, Concepción, dir. (1993): Diccionario didáctico del español. Intermedio, Madrid, SM.

NOVÍSIMO DICCIONARIO (1846): Novísimo diccionario manual de la lengua castellana por una sociedad de literatos, Barcelona, Imprenta del Fomento.

PiCAtoste, Felipe (1882): Diccionario popular de la lengua castellana, Madrid, G. Estrada. 
Pla y TORRES, Cristóbal (1840² [1826]): Diccionario de la lengua castellana por La Academia Española, Madrid, Librería Ramos.

Real ACADEMia EsPañola (2001): Nuevo Tesoro Lexicográfico (NTLLE), Madrid, Espasa Calpe [edición en DVD]

\section{OTRAS REFERENCIAS BIBLIOGRÁFICAS}

AhumADA, Ignacio (2007): «Bibliografía de la metalexicografía del español: la crítica de diccionarios (ss. XVI al XIX)», en M. Campos Souto et alii, eds., Historia de la lexicografía española, A Coruña, Universidad de A Coruña, Anexos de la Revista de Lexicografia, pp. 9-20.

ANGLADA, Emilia y María BARGALló (1992): «Principios de lexicografía moderna en diccionarios del siglo XIX», en Actas del II Congreso Internacional de Historia de la Lengua Española, Madrid, Arco/Libros, I, pp. 955-962.

AZORÍN FERNÁNDEZ, Dolores (1996-1997): «La lexicografía española en el siglo XIX: del diccionario a la enciclopedia», Estudios de Lingüística, 11, pp. 111-122.

(2000): Los diccionarios en su perspectiva histórica, Alicante, Universidad de Alicante.

(2006): «La lexicografía monolingüe no académica del siglo XIX» [www.liceus.com]

y Rosario BAquero Mesa (1992): «Los americanismos en el Nuevo diccionario de la lengua castellana de Vicente Salvá», en Actas del II Congreso Internacional de Historia de la Lengua Española, Madrid, Arco/Libros, II, pp. 963-970.

CAPITÁN DíAZ, Alfonso (2002): Breve historia de la educación en España, Madrid, AlianZa.

HAENSCH, Günther y Carlos OMEÑACA (2004): Los diccionarios del español en el siglo XXI, Salamanca, Universidad de Salamanca.

Hernando CuAdrado, Luis Alberto (1997) «El Diccionario de Autoridades (1726-1739) y su evolución», Verba, 24, pp. 387-401.

MARTÍNEZ MARÍN, Juan (2000): «La lexicografía monolingüe del español en el siglo XIX: la corriente no académica», en I. Ahumada, ed., Cinco siglos de lexicografía del español, Jaén, Universidad de Jaén, pp. 63-77. 
Pruvost, Jean (2002): Les dictionnaires de langue française, Paris, Presses Universitaires de France.

SECO, Manuel (2003): Estudios de lexicografia española, Madrid, Gredos. 